\title{
FOTOSSÍNTESE, REMOBILIZAÇÃO DE RESERVAS E CRESCIMENTO DE GRÃOS EM DOIS HÍBRIDOS DE MILHO SOB DEFICIÊNCIA HÍDRICA NA FASE DE ENCHIMENTO DOS GRÃOS $\left(^{1}\right.$ )
}

\author{
EDUARDO CARUSO MACHADO (2.6), JOAQUIM ALBENISIO GOMES DA SILVEIRA $(3,6)$, \\ VICTOR ALEXANDRE VTTORELLO $\left(^{4,6}\right)$ e JORGE LUIZ MAZZA RODRIGUES $\left(^{5,6}\right)$
}

\begin{abstract}
RESUMO
Foram avaliados, em dois hibridos simples de milho (Zea mays L.), Pioneer 3072 e IAC $701 \times \mathrm{B}$, submetidos à deficiencia hídrica, o comportamento da fotossíntese, da remobilização de N e de açúcares durante o período de crescimento dos grăos. As plantas foram cultivadas sob condiçôes naturais, em doze tanques de alvenaria $(4 \mathrm{~m}$ de comprimento $\times 0,5 \mathrm{~m}$ de largura $\times 0,6$ m de profundidade) contendo terra. A deficiência hídrica foi induzida entre o 5. e o 15. dia após a floraçăo, suspendendo-se a irrigação. Sem deficiência hídrica, ambos os híbridos apresentaram comportamento semelhante quanto aos parametros avaliados. Sob deficiência hídrica, a remobilizaçăo de açúcares e de $\mathbf{N}$, a partir dos órgãos vegetativos para os grăos, foi mais intensa que nas plantas-controle, sem deficiência hídrica, e mais acentuada, tanto em açúcares como em $\mathbf{N}$, no híbrido IAC $701 \times$ B. Sob deficiência hídrica, a taxa de fotossíntese diminuiu em ambos os hibridos, sobretudo no IAC $701 \times$ B.
\end{abstract}

Termos de indexaçäo: milho, Zea mays L., deficiência hídrica, trocas gasasas, crescimento, açúcares, nitrogenio.

\section{ABSTRACT \\ PHOTOSYNTHESIS, RESERVES REMOBILIZATION AND GRAIN GROWTH OF TWO MAIZE HYBRIDS SUBMITED TO WATER STRESS DURING THE GRAIN FILLING STAGE}

\begin{abstract}
Photosynthesis, nitrogen and sugar remobilization during the grain filling period were examined in two maize (Zea mays L.) hybrids (Pioneer 3072 and IAC $701 \times$ B) submited to water stress. The plants were grown under natural conditions in 12 boxes ( $4 \mathrm{~m} \times 0.5 \mathrm{~m} \times 0.6 \mathrm{~m}$ each) containing soil. Water stress was imposed by with holding irrigation during the $5^{\text {th }}$ and $15^{\text {th }}$ days after anthesis. Both hybrids in control treatment (without water stress) showed no differences in relation to the avaliated parameters. Under water stress the sugar and $\mathbf{N}$ remobilization from vegetative organs to the grains, were more intense than of the control plants. The sugar and $\mathrm{N}$ remobilization were larger in IAC $701 \times$ B. The photosynthesis rates were reduced in both hybrids under water stress, but the reduction was larger in IAC $701 \times B$.
\end{abstract}

Index terms: maize, Zea mays L., water stress, $\mathrm{CO}_{2}$ exchange, growth, sugar, nitrogen.

$\left({ }^{1}\right)$ Trabalho parcialmente financiado pela FAPESP e pelo CNPq. Recebido para publicação em 16 de setembro e aceito em 10 de dezembro de 1992.

(3) Seção de Fisiologia, Instituto Agronômico de Campinas (IAC), Caixa Postal 28, 13001-970 Campinas (SP).

(3) Universidade Federal do Ceará, Departamento de Bioquímica e Biologia Molecular, Caixa Postal 1065, 60001 Fortaleza (CE).

() CENA-ESALQ, Departamento de Bioquímica, Caixa Postal 9, 13400-970 Piracicaba (SP).

(5) Pós-graduado, CENA-ESALQ, Departamento de Bioquímica.

() Bolsista do CNPq.

Bragantia, Campinas, 51(2):151-159, 1992 


\section{INTRODUÇÃO}

A ocorrência de deficiência hídrica durante a estação de crescimento das plantas é um dos fatores ambientais que mais afetam a estabilidade da produção de grãos em cereais. Em milho, a redução da produção de grãos em função da ocorrência de seca depende do estádio de desenvolvimento da planta, da intensidade e duração da seca e da sensibilidade do cultivar (Lorens et al., 1987). Cultivares com diferentes sensibilidades à seca são relatados na literatura (Frederick et al., 1990).

Quantitativamente, o crescimento dos grãos pode ser avaliado em termos da capacidade da planta em suprir substrato para o crescimento (fonte) e do potencial dos grãos (dreno) em acumular o substrato disponível (Tollenaar, 1977). Identificam-se duas fontes principais de substrato para o crescimento dos grãos: uma originada a partir da produção fotossintética após a antese e outra relacionada com a remobilização de material assimilado antes da antese e temporariamente armazenado, principalmente nos colmos. Tanto a produção fotossintética como a remobilização de reservas são afetadas durante a seca (McPherson \& Boyer, 1977).

Em condições normais a produção de grãos é proporcional à produção fotossintética pós-antese. Sob deficiência hídrica, porém, a fotossíntese é severamente inibida, enquanto a translocaçāo é menos afetada (McPherson \& Boyer, 1977; Westgate \& Boyer, 1985; Quattar et al., 1987), tornando-se importante a contribuição das reservas remobilizadas para os grãos. McPherson \& Boyer (1977) observaram que, sob deficiência hídrica severa durante o período de granaçāo, apesar de a fotossíntese ser nula, a produção de grãos variou entre 47 e $67 \%$ das plantas-controle, sem deficiência hídrica.

A produtividade do milho está associada com a atividade metabólica do carbono e do nitrogênio, tendo este um papel direto na acumulação de matéria seca nos grãos (Below et al., 1981; Swank et al., 1982). Frederick et al. (1990) observaram que híbridos de milho que mantêm a capacidade de absorver e assimilar o $\mathbf{N}$ e de produzir açúcares nas fases mais adiantadas do período de enchimento de grãos, apresentam maior tolerância à seca.
Neste trabalho, analisou-se, em dois híbridos simples de milho, IAC 701 x B e Pioneer 3072, submetidos à deficiência hídrica na fase inicial de enchimento dos grãos, o acúmulo de fitomassa, de remobilização de açúcares e de $\mathbf{N}$ e a taxa de fotossíntese.

\section{MATERIAL E MÉTODOS}

Foram utilizados dois híbridos simples de milho, Pioneer 3072, de porte baixo e precoce, e IAC $701 \times$ B, de porte médio e ciclo cerca de sete dias mais longo. As plantas foram cultivadas em doze tanques de alvenaria contendo terra com as seguintes características químicas: $\mathbf{p H} 5,8 ; 0,9 \%$ de matéria orgânica; $1,5 \mu \mathrm{g}$ de $\mathrm{P} / \mathrm{cm}^{3}$ e $0,04,1,4$ e $0,5 \mathrm{meq} / 100$ $\mathrm{cm}^{3}$, respectivamente, de $\mathrm{K}, \mathrm{Ca}$ e $\mathrm{Mg}$. Os tanques, representando as parcelas, tinham as seguintes dimensōes: $4,0 \mathrm{~m}$ de comprimento por $0,5 \mathrm{~m}$ de largura por $0,6 \mathrm{~m}$ de profundidade (área $-2 \mathrm{~m}^{2}$ ), estando dispostos paralelamente e distantes uns dos outros $40 \mathrm{~cm}$. A terra neles contida foi adubada, por incorporação superficial $(10 \mathrm{~cm})$, por metro quadrado, com $32 \mathrm{~g}$ de $\mathrm{P}_{2} \mathrm{O}_{5}$ (superfosfato simples); $8 \mathrm{~g}$ de $\mathrm{K}_{2} \mathrm{O}$ (cloreto de potássio); $4 \mathrm{~g}$ de $\mathrm{N}$ (sulfato de amônio) e $2 \mathrm{~g}$ de sulfato de zinco. Trinta dias antes da semeadura, foram incorporados $50 \mathrm{~g} / \mathrm{m}^{2}$ de Minercal. Quarenta dias após a semeadura, aplicaram-se $10 \mathrm{~g} / \mathrm{m}^{2}$ de $\mathrm{N}$ (sulfato de amônio) em cobertura. As plantas cresceram sob condições naturais, no Centro Experimental de Campinas (IAC).

Com o objetivo de fazer coincidir a floração dos dois híbridos, efetuaram-se duas semeaduras, uma em 5/11/90 (IAC $701 \times$ B) e outra, em 13/11/90 (Pioneer 3072), no centro do tanque, mantendo-se, após a raleação, seis plantas/metro linear.

O delineamento experimental foi em parcelas subdivididas, cujos tratamentos foram representados por dois níveis de umidade do solo e os subtratamentos, pelos dois híbridos. $\mathrm{A}$ área da parcela era de $2 \mathrm{~m}^{2}$ e a da subparcela, de $1 \mathrm{~m}^{2}$.

Em um dos tratamentos, a umidade do solo foi mantida ao redor de $33 \%$ (massa/massa, equivalente a um potencial da água $\cong 0,01 \mathrm{MPa}$ ), durante todo o ciclo de desenvolvimento das plantas. 
No outro, a irrigação foi suspensa no $5^{\circ}$ dia após a floração (22/1/90), até que a terra atingisse a umidade de $20 \%$ na profundidade de $30 \mathrm{~cm}$ (potencial da água $\cong 0,5 \mathrm{MPa}$ ). Após o solo ter atingido a umidade de $20 \%(1 \% / 2 / 91)$, os tanques foram novamente irrigados até o final do estudo, de forma a não ocorrer mais deficiência hídrica. O potencial da água no solo, em função da umidade, foi estimado a partir de curva de retenção de água (Reichardt, 1985), sendo a umidade medida pelo método gravimétrico (Reichardt, 1985).

Em dias chuvosos, os tanques eram cobertos com lona plástica, ao nível do solo, impedindo a penetração de água.

No período compreendido entre a floração (18/1/91) e a maturação ( $1 \% / 3 / 91)$, efetuaram-se cinco coletas destrutivas de plantas, as quais foram cortadas ao nível do solo. Cada coleta foi feita com cinco repetições (duas plantas/repetição). As plantas foram separadas em folhas verdes, folhas senescentes, colmos + bainhas, espigas e grāos, sendo a massa seca de cada parte medida após secagem, por sete dias, em estufa com circulação forçada de ar a $70^{\circ} \mathrm{C}$.
As folhas verdes e as senescentes, os colmos + bainhas e os grāos foram moídos até 20 mesh, determinando-se os teores de $\mathrm{N}$ total e de açúcares. O N total foi medido utilizando-se o método de Kjeldahl e os açúcares, o da antrona, descritos por Yoshida et al. (1971).

Em quatro datas, durante o desenvolvimento da deficiência hídrica $(18,21,24$ e 25 de janeiro) e em uma data após o reinício da irrigação (4/1), em intervalos de uma hora, no período entre as 7 e as $13 \mathrm{~h}$, mediu-se a taxa de fotossintese da folha inserida na base da espiga, com cinco repetiçōes, mediante um analisador de $\mathrm{CO}_{2}$ portátil (LI-COR 6200) em plantas intactas sob condiçōes naturais.

\section{RESULTADOS E DISCUSSĀO}

O acúmulo de fitomassa seca após a floração é apresentado na figura 1.

Sem deficiência hídrica, os padrōes de acúmulo de fitomassa foram semelhantes para ambos. $\mathrm{Na}$ maturação, a fitomassa total (MST) e a dos grãos (MSG)acumulados foram, respectivamente, 235,2 $\mathrm{g}$

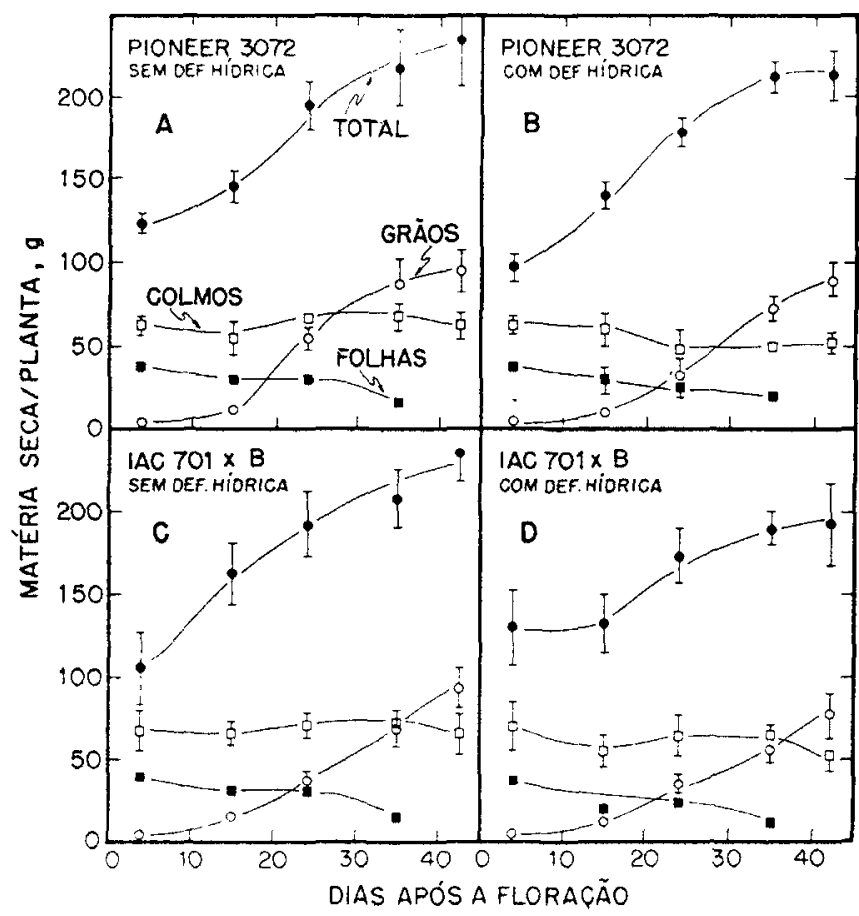

Figura 1. Acúmulo de fitomassa seca, após a floração, nos híbridos simples Pioneer 3072 (A e B) e IAC 701 x B (C c D), submetidos à đeficiência hídrica entre o $5^{\circ}$ e o $15^{\circ}$ dia após a floraçāo. Cada ponto representa a média đe cinco repetiçōes e as barras, o erro padrāo. Campinas, 1990/91. 
de MST/planta e 95,0 g de MSG/planta para o IAC e $234,2 \mathrm{~g}$ de $\mathrm{MST} /$ planta e $95,0 \mathrm{~g}$ de MSG/planta para o Pioneer. Na floraçāo, os dois apresentaram a mesma quantidade de folhas ativas $3(37,0 \mathrm{~g}$ de $\mathrm{MSF} /$ planta), isto é, possuíam aproximadamente a mesma dimensão para o aparelho fotossintético (fonte).

Entre a floração (1. coleta) e a maturação (5.), o LAC produziu, por planta, 106,8 g de MST e 92,9 $\mathrm{g}$ de MSG, e o Pioneer, $113,0 \mathrm{~g}$ de MST e $93,8 \mathrm{~g}$ de MSG (Quadro 1). Tais resultados indicam, portanto, que os dois híbridos apresentaram a mesma capacidade produtiva.

Sob deficiência hídrica, a produção de MST e de MSG foram, repectivamente, por planta, $18 \%$ $(194,2 \mathrm{~g})$ e $24 \%(71,1 \mathrm{~g})$ menores no $\mathrm{IAC}$, e, no Pioneer, $12 \%(208,6 \mathrm{~g})$ e $9 \%(86,5 \mathrm{~g})$ menores em relação aos respectivos controles. Comparativamente, o Pioneer produziu 7\% mais MST e $22 \%$ mais grãos.

Entre a floração e a maturação, sob deficiência hídrica, por planta, o IAC produziu $65,2 \mathrm{~g}$ de MST e 74,9 $\mathrm{g}$ de $\mathrm{MSG}$, indicando que o crescimento dos grãos foi 1,15 vez maior que a produção total de fotossintetizados (Quadro 1), ou seja, a produçāo fotossintética após a floração foi insuficiente para atender ao crescimento dos grảos e das outras estruturas que compōem a espiga do milho. Assim, é provável que parte do substrato utilizado para o crescimento das espigas (grãos + sabugo + palhas) tenha sido originado a partir da remobilização de reservas dos colmos, visto que, na floração, eles pesaram, por planta, $68,6 \mathrm{~g}$ e, na maturação, 52,0 $\mathrm{g}$, isto é, perderam 16,1 g/planta (Quadro 1).

Observa-se também - Figura 2 - que no híbrido IAC a quantidade de carboidratos diminuiu acentuadamente após a floração, sugerindo que a queda na massa dos colmos foi devida, principalmente, à remobilização de carboidratos não estruturais.

No híbrido Pioneer, sob deficiência hídrica, as produçōes de MST e de MSG foram, respectivamente, por planta, de $85,4 \mathrm{~g}$ e $85,3 \mathrm{~g}$. Também neste caso, observou-se que os colmos, entre a floraçāo e a maturação, perderam 10,5 g/planta, e a concentração de carboidratos caiu mais acentuadamente que nos controles (Quadro 1 e Figura 2).

Em milho, ao redor do período da antese, geralmente a produçāo de fotossintetizados é maior que aquela demandada pelos órgãos reprodutivos, sendo o excesso de fotoassimilados armazenado

Quadro 1. Acúmulo de fitomassa seca nos grãos ( $\triangle M S G)$, nos colmos $(\Delta M S C)$ e total $(\Delta M S T)$ entre a floração e a maturação, em dois híbridos simples de milho, LAC 701 x B e Pioneer 3072, submetidos à deficiência hídrica entre o $5^{\circ}$ e o $15^{\circ}$ dia após a floraçāo. Campinas 1990/91

Fitomassa seca

\begin{tabular}{lcccr} 
& \multicolumn{2}{c}{ Controle } & & \multicolumn{2}{c}{ Com deficiência hídrica } \\
\cline { 2 - 5 } & IAC & Pioneer & IAC & Pioneer \\
\cline { 2 - 5 } & & & & \\
& 106,8 & 113,0 & $65,2(0,61)\left({ }^{2}\right)$ & $85,4(0,76)$ \\
$\Delta M S T$ & $-2,5$ & $-0,3$ & $-16,1$ & $-10,5$ \\
$\Delta M S C$ & 92,9 & 93,8 & $74,9(0,81)$ & $85,3(0,91)$ \\
$\Delta M S G$ & 1,15 & 1,20 & 0,81 & 1,00
\end{tabular}

(1) $\Delta$ indica diferença de massa entre a floração e a maturação.

(2) Os números entre parênteses indicam valor relativo entre a produçāo de massa nas plantas sob deficiência hídrica e nas plantas-controle. 
como reserva, principalmente nos colmos e bainhas (Duncan, 1975). Posteriormente, durante o período de crescimento intenso dos grãos, se a produção de fotossintetizados for insuficiente para atender à demanda dos grãos, as reservas podem ser remobilizadas e utilizadas como fonte suplementar (Tollenaar, 1977; Machado et al., 1982). Observa-se, na figura 2 , que, sob deficiência hídrica, a remobilização de reservas a partir dos colmos foi mais intensa que nas plantas-controle, sobretudo no híbrido IAC. A remobilização intensa de reservas em plantas sob deficiência hídrica também foi relatada por outros autores, como McPherson \& Boyer (1977) e Westgate \& Boyer (1985), minorando os efeitos da seca. Em outros trabalhos, como no presente, notaram-se diferenças varietais quanto à intensidade de remobilização de reservas para o crescimento dos grãos (Turner \& Begg, 1981).

A figura 3 mostra o comportamento das taxas de fotossíntese em função da radiação solar, medidas antes, durante e após a ocorrência da deficiência hídrica.

As curvas de resposta da taxa de fotossíntese, nas plantas sem deficiência hídrica, em função da radiação solar, apresentaram a forma de uma hipérbole retangular, típica para o milho (Duncan, 1975; Dwyer \& Stewart, 1986).

Sem deficiência hídrica, embora a fotossíntese seja afetada por fatores como temperatura e concentração de $\mathrm{CO}_{2}$ no ar, a curva de resposta em condiçōes naturais é determinada principalmente pela variação da radiação solar durante o dia (Marshall \& Biscoe, 1980).

Sob deficiência hídrica, as plantas dos dois híbridos apresentaram menores taxas de fotossíntese que aquelas sem deficiência hídrica (Figura 3). Entretanto, ficou evidenciado que as maiores quedas ocorreram no híbrido IAC. Já no segundo dia sob deficiência hídrica (24/1/91), a taxa fotossintética respondeu ao aumento da radiação solar somente até ao redor de $700 \mu \mathrm{E} \cdot \mathrm{m}^{-2} \cdot \mathrm{s}^{-1}$. Em irradiâncias maiores, que ocorrem nas horas mais próximas do meio-dia, a fotossíntese diminuiu, possivelmente devido ao aumento da temperatura e do déficit de pressão de vapor no ar. Ainda em 24/1/91, a taxa de fotossíntese no Pioneer, apesar de menor que nas plantas-controle, nāo apresentou quedas tão acentuadas. Nos dias subseqüentes, a fotossíntese do IAC foi sempre menor (Figura 3).

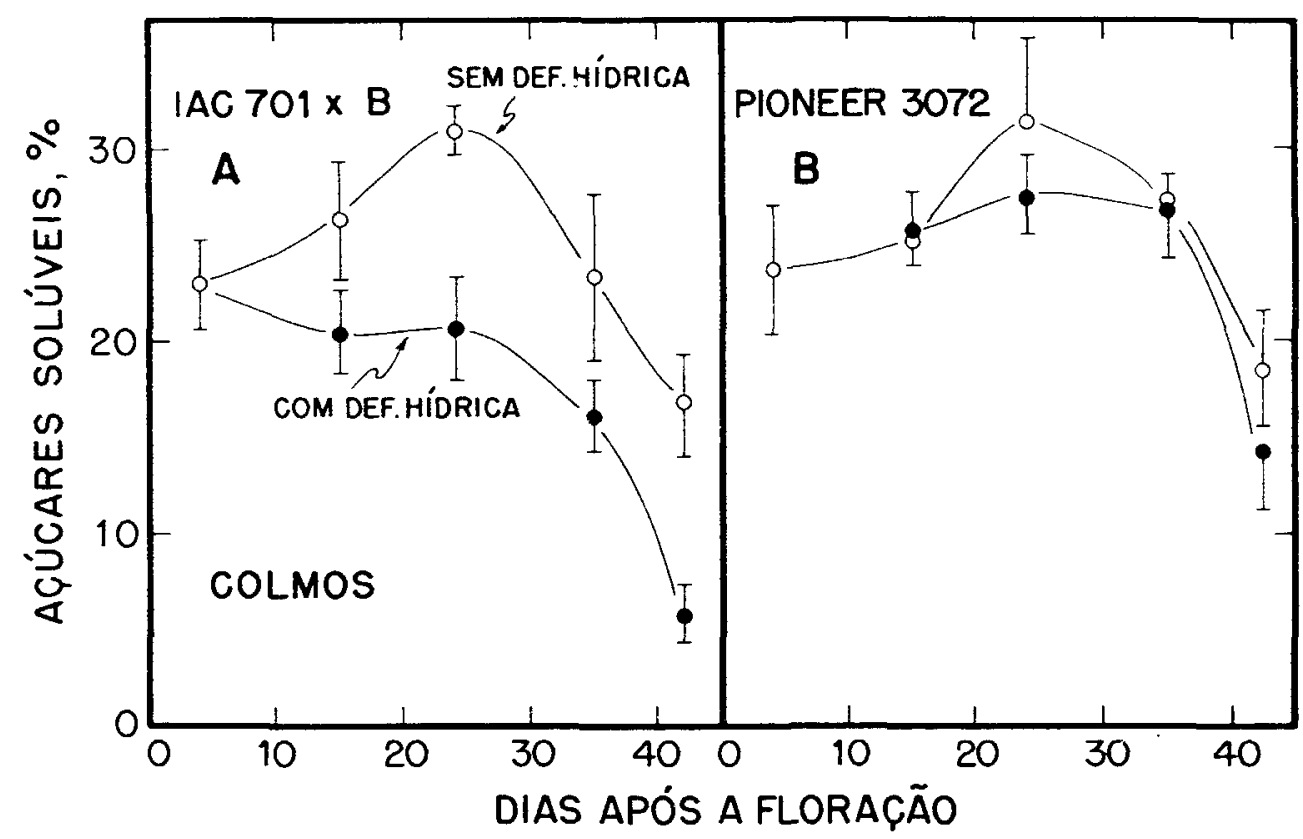

Figura 2. Porcentagem de açúcares solúveis nos colmos de dois hôridos simples de milho, IAC $701 \times$ B (A) e Pioneer 3072

(B), submetidos à deficiéncia hídrica entre o $5^{\circ}$ e $\circ 15^{\circ}$ dia após a floraçáo. Cađa ponto representa a média đe quatro repetiçőes e as barras, o erro padrăo. Campinas, 1990/91. 


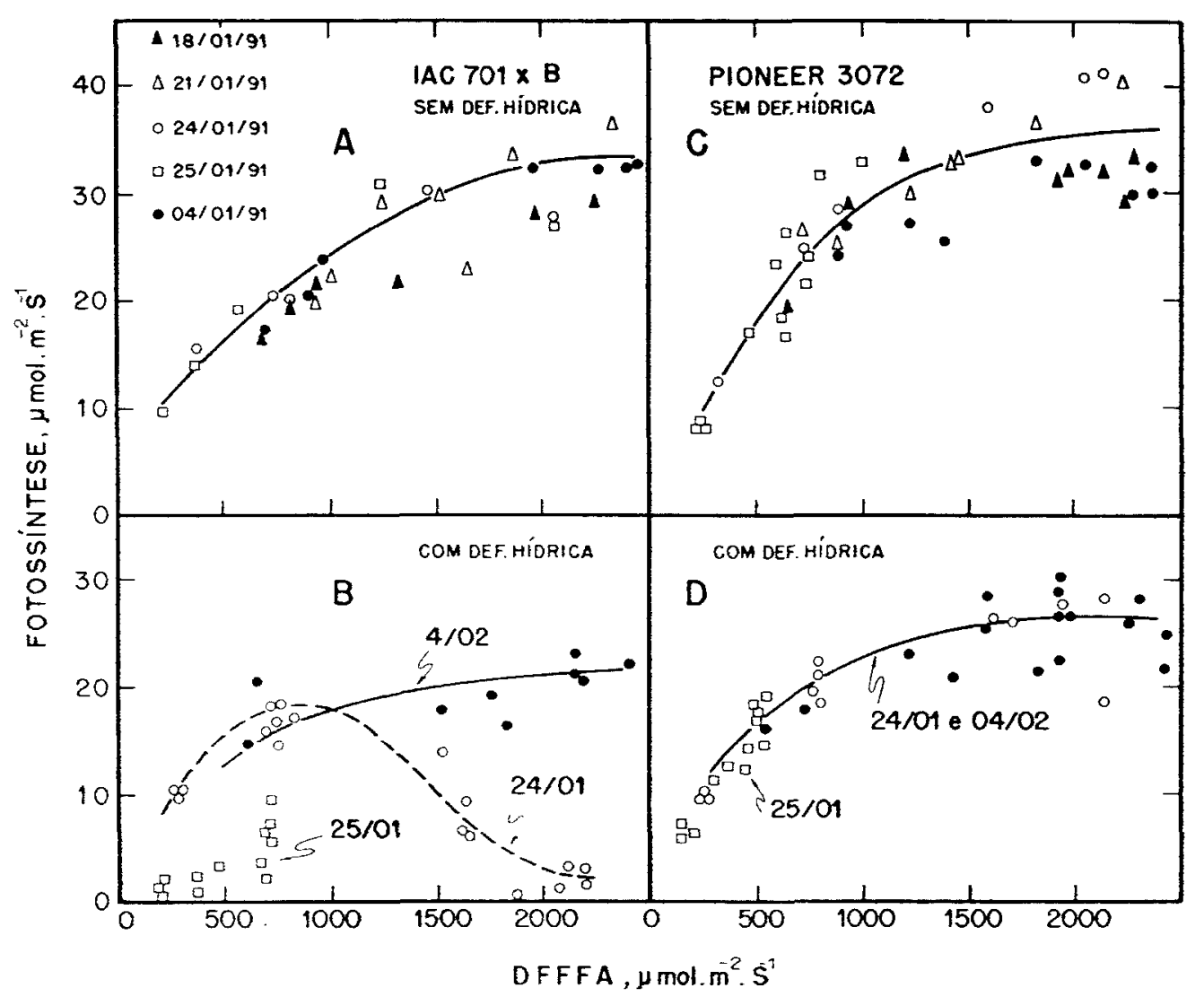

Figura 3. Taxas de fotossíntese, em função da densidade de fluxo de fótons fotossinteticamente ativos (DFFFA) nos híbridos simples LAC 701 x B (A e B) e Pioneer 3072 (C e D) submetidos à defíciéncia hídrica entre o 5. e o 15. dia após a floração. Campinas, 1990/91: $(\Delta, \Delta)$, antes da suspensāo da irrigação; $(O, \square)$, respectivamente $2^{\circ}$ e $3^{\circ}$. dia após a suspensão da irrigação; (†), dois dias após o reinício da irrigaçăo.

Dois dias após o reinício da irrigação (4/2/91), ambos os híbridos recuperaram parcialmente a capacidade fotossintética, mas, também neste caso, a recuperação foi maior no Pioneer.

A figura 4 mostra o acúmulo de $\mathrm{N}$ total nas diferentes partes das plantas entre a floraçāo e a maturaçāo.

Sem deficiência hídrica, o Pioneer absorveu, entre a $1^{\text {a }}$ e a $5^{\mathrm{a}}$. coleta, por planta, $0,787 \mathrm{~g}$ de $\mathrm{N}$, e o IAC, $0,982 \mathrm{~g}$ de $\mathrm{N}$ e, sob deficiência hídrica, respectivamente, $0,705 \mathrm{~g}$ de $\mathrm{N}$ e $0,683 \mathrm{~g}$ de $\mathrm{N}$ - Quadro 2. Sob deficiência hídrica, o IAC acumulou $30 \%$ menos $\mathrm{N}$ em relação ao controle, enquanto o Pioneer acumulou $10 \%$ menos.

Nas plantas-controle, o acúmulo de $\mathrm{N}$, por planta, nos grãos do Pioneer, foi de $1,496 \mathrm{~g} \mathrm{e}$, no
IAC, 1,650 g, indicando que o $\mathrm{N}$ absorvido após a floração contribuiu, respectivamente, com 53 e 60\% do $\mathrm{N}$ acumulado nos grāos (Quadro 2). Nesses híbridos, portanto, as atividades de absorção, redução e assimilaçāo do $\mathbf{N}$ não foram suficientes para atender à demanda dos grãos. Assim, para o crescimento destes foi necessária a contribuição de fonte alternativa, possivelmente representada pela remobilização de $\mathbf{N}$ a partir de folhas e, em menor escala, dos colmos (Quadro 2), visto que a quantidade de $\mathrm{N}$ decresceu continuamente nesses órgãos - Figura 4. Swank et al. (1982), comparando cinco híbridos de milho, também verificaram que o $\mathrm{N}$ remobilizado representou entre 50 e $80 \%$ da necessidade dos grãos.

A contribuição do $\mathbf{N}$ remobilizado das folhas para os grãos foi, por planta, de $0,409 \mathrm{~g}$ (25\% do 


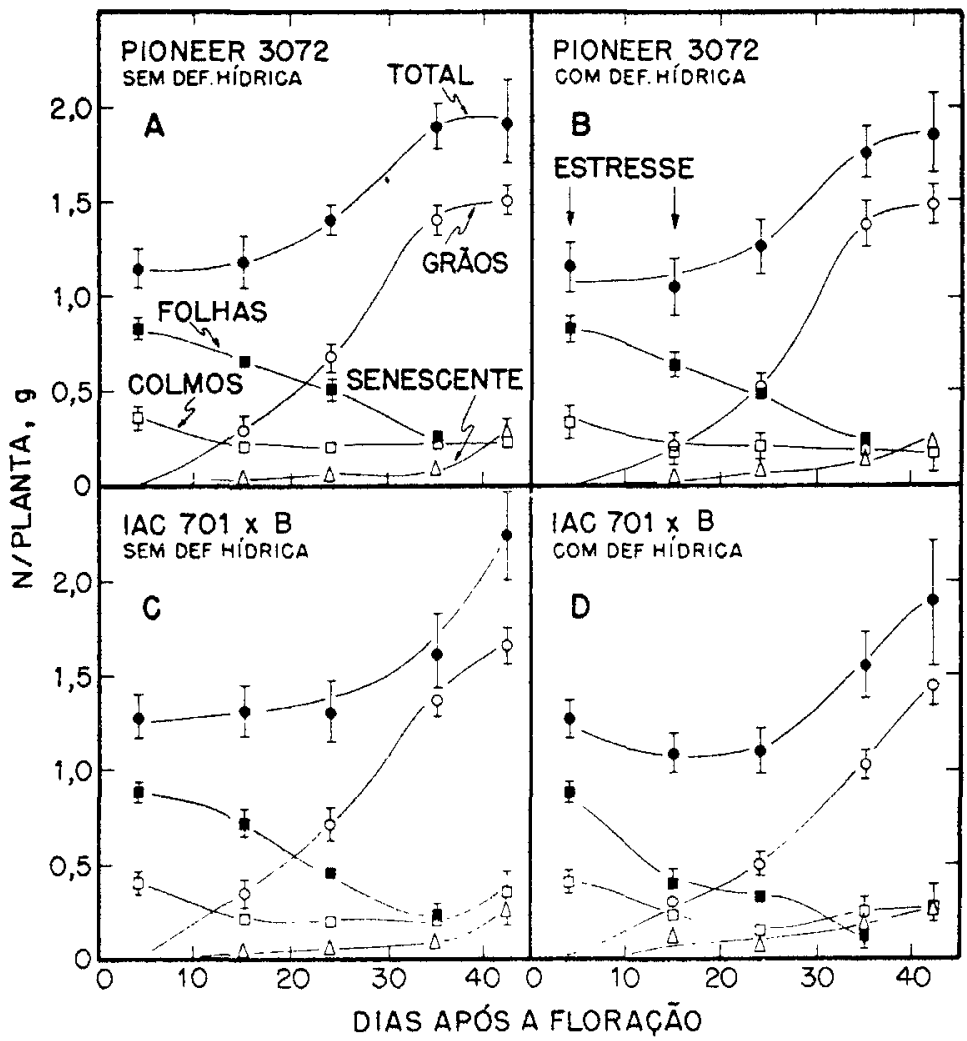

Figura 4. Acúmulo de $\mathrm{N}$ nas diversas partes dos híbridos simples Pioneer 3072 (A e B) e IAC 701 x B (C e D) submetidos à deficiéncia hídrica entre o $5^{\circ}$ e o $15^{\circ}$. dia após a floraçāo. Cada ponto representa a média de quatro repetiçőes e as barras, o erro padrăo. Campinas, 1990/91.

Quadro 2. Acúmulo de $\mathrm{N}$ total na planta inteira $\left(\Delta \mathrm{N}_{\mathrm{T}}\right)$, nas folhas $\left(\Delta \mathrm{N}_{\mathrm{F}}\right)$, nas folhas senescentes $\left(\Delta \mathrm{N}_{S}\right)$, nos colmos $\left(\Delta N_{C}\right)$ e nos grãos $\left(\Delta N_{G}\right)$, entre a floração e a maturação, em dois híbridos simples de milho, IAC 701 x B e Pioneer 3072, submetidos à deficiência hídrica entre o $5^{\circ}$ e o 15. dia após a floração. Campinas, 1990/91

Nitrogênio total

\begin{tabular}{|c|c|c|c|c|}
\hline \multirow[t]{2}{*}{ Parâmetros $\left({ }^{1}\right)$} & \multicolumn{2}{|c|}{ Controle } & \multicolumn{2}{|c|}{ Com deficiência hídrica } \\
\hline & IAC & Pioneer & IAC & Pioneer \\
\hline & \multicolumn{4}{|c|}{ g/planta } \\
\hline$\Delta \mathbf{N T}_{\mathbf{T}}$ & 0,982 & 0,787 & 0,683 & 0,705 \\
\hline$\Delta \mathrm{NF}_{\mathrm{F}}$ & $-0,657$ & $-0,561$ & $-0,769$ & $-0,565$ \\
\hline$\Delta \mathrm{Ns}$ & 0,248 & 0,252 & 0,242 & 0,211 \\
\hline$\Delta \mathbf{N}_{\mathbf{C}}$ & $-0,044$ & $-0,139$ & $-0,155$ & $-0,163$ \\
\hline$\Delta N_{G}$ & 1,650 & 1,496 & 1,468 & 1,477 \\
\hline$\Delta \mathbf{N T}_{\mathrm{T}} / \mathbf{N}_{\mathbf{G}}$ & 0,60 & 0,53 & 0,47 & 0,48 \\
\hline
\end{tabular}

( $\left.{ }^{1}\right) \Delta$ indica diferença na quantidade de $\mathrm{N}$ total entre a floração e a maturaçăo. 
total de $\mathrm{N}$ para os grãos) e $0,309 \mathrm{~g}(21 \%)$ para o IAC e Pioneer, enquanto a contribuição dos colmos foi, por planta, respectivamente, $0,139 \mathrm{~g}$ (18\%) e $0,044 \mathrm{~g} \mathrm{(3 \% )} \mathrm{(Quadro} \mathrm{2),} \mathrm{no} \mathrm{tratamen-}$ to-controle.

Sob deficiência hídrica, os grãos do IAC acumularam, por planta, $1,468 \mathrm{~g}$ de $\mathrm{N}$, indicando que o $\mathrm{N}$ absorvido após a floração, por planta $(0,705$ g para o Pioneer e 0,683 g para o IAC), representou, respectivamente, 47 e $48 \%$ da demanda de $\mathrm{N}$ pelos grãos, isto é, o $\mathrm{N}$ remobilizado dos colmos e das folhas contribuiu ainda mais na formação do substrato nitrogenado para os grãos do que nas plantas sob deficiência. Bataglia (1980) também observou, em milho, que a contribuição de $\mathrm{N}$ remobilizado para atender à demanda dos grãos foi maior em plantas sob deficiência hídrica que nas plantas irrigadas. Frederick et al. (1990) porém, ainda em milho, observaram que, devido à grande demanda por $\mathbf{N}$ pelos grãos em plantas não deficientes em água, o $\mathrm{N}$ remobilizado foi mais importante que nas plantas sob deficiência hídrica. Resultados diferentes, na literatura (Bataglia, 1980: Frederick et al., 1990) sugerem que há variabilidade genética quanto ao aproveitamento do $\mathrm{N}$, bem como influência do ambiente e da época da deficiência hídrica. Frederick et al. (1990) aplicaram o estresse hídrico por um período mais longo e incluíram a floração, o que acarreta menor fecundação de óvulos e queda mais acentuada na produção de grãos. No caso presente, o potencial de dreno (óvulos fecundados e potencialmente viáveis) foi semelhante nos dois tratamentos, visto que, em ambos, ocorreu em condiçōes ideais. No trabalho de Frederick et al. (1990), isso nāo aconteceu, sendo a demanda por $\mathbf{N}$ das plantas sob deficiência hídrica muito menor do que daquelas sem deficiência.

Sob deficiência hídrica, a contribuição do $\mathrm{N}$ remobilizado a partir das folhas para os gräos foi maior no IAC $(0,527 \mathrm{~g} /$ planta, $36 \%$ do total acumulado nos grãos) que no Pioneer $(0,354 \mathrm{~g} / \mathrm{planta}$, 24\%). É possível, conseqüentemente, que exista uma relação entre maior remobilização de $\mathbf{N}$ das folhas, maior queda na taxa de fotossíntese e menor absorção de novo $\mathrm{N}$, quando se comparam os resultados dos híbridos IAC e Pioneer (Quadros 1 e 2; Figuras 3 e 4). Tem-se demonstrado uma relaçāo direta entre concentração de $\mathbf{N}$ da folha e a taxa de fotossíntese (Bataglia, 1980).

No caso presente, apesar de os padrōes de comportamento do acúmulo e da remobilização do $\mathbf{N}$, durante o período de enchimento dos grãos, serem semelhantes, sob deficiência hídrica a remobilizaçáo do $\mathrm{N}$ parece ter sido mais importante na formação do substrato nitrogenado para os grãos no IAC.

\section{CONCLUSÕES}

Sob condições de clima e solo não limitantes, os híbridos simples IAC 701 x B e Pioneer 3072 apresentaram potencial produtivo semelhante. Quando submetidos à deficiência hídrica entre o 5. e o 15. dia após a floração, o Pioneer 3072 mostrou queda relativamente menor na produção de fitomassa total e de grãos.

Em ambos os híbridos, mesmo em condiçōes normais, houve remobilização tanto de carboidratos como de N, a partir dos órgãos vegetativos para os reprodutivos, principalmente durante o intenso enchimento dos gräos. Isso sugere que, nesse período, tanto a produçāo fotossintética como a atividade de absorção e assimilação de $\mathrm{N}$ foram insuficientes para atender à demanda dos grãos. Tanto para os açúcares como para o $\mathrm{N}$, a remobilização foi mais intensa no IAC $701 \times$ B.

Sob deficiência hídrica, as remobilizações de carboidratos e de $\mathbf{N}$ foram mais intensas que nas plantas-controle, indicando a maior importância relativa desse processo.

Nas plantas sob deficiência hídrica, as remobilizaçōes de carboidratos e de N no IAC 701 x B foram mais acentuadas.

Esses resultados indicam que os híbridos analisados apresentaram diferentes estratégias diante da ocorrência de seca: enquanto o IAC 701 $x$ B apresentou maior capacidade de remobilização de nutrientes, o Pioneer 3072 revelou queda relativamente menor na taxa de fotossíntese. 


\section{REFERENCIAS BIBLIOGRÁFICAS}

BATAGLIA, O.C. Enects of nitrogen-water relations on maize productivity. Davis, 1980. 182p. Tese (Doutorado) - University of California, 1980.

BELOW,F.E; CHRISTENSEN, L.E; REED, A.J. \& HAGEMAN, R.H. Availability of reduced $\mathrm{N}$ and carbohydrates for ear development of maize. Plant Physiology, Lancaster, 68(5):1186--1190, 1981.

DUNCAN, W.G. Maize. In: EVANS, LT., ed. Crop physiology: some Case histories. London, Cambridge University Press, 1975. cap. 2, p.23-50.

DWYER, L.M. \& STEWART, D.W. Effect of leaf age and position on net photosynthetic rates in maize (Zea mays Ln). Agricultural and Forest Meteorology, Amsterdam, 37(1):29-46, 1986.

FREDERICK, J.R; BELOW, F.E. \& HESKETH, J.D. Carbohydrate, nitrogen and dry matter accumulation and partitioning of maize hybrids under drought stress. Annals of Botany, London, 66(4):407-415, 1990.

LORENS, G.F.; BENNETT, J.M. \& LOGGALE, L.B. Differences in drought resistence between two corn hybrids: II. Component analysis and growth rates. Agronomy Journal, Madison, 79(5):808-813, 1987.

MACHADO, E.C.; PEREIRA, A.R;; FAHL, J.I; ARRUDA, H.V.; SILVA, W.J. da \& TEIXEIRA, J.P.F. Análise quantitativa de crescimento de quatro variedades de milho em tres densidades de plantio, através de funçōes matemáticas ajustadas. Pesquisa Agropecuária Brasiletra, Brasilia, 17(6):825-833, 1982.
McPHERSON, H.G. \& BOYER, J.S. Regulation of grain yield by photosynthesis in maize subjected to a water deficiency. Agronomy Journal, Madison, 69(4):714-718, 1977.

MARSHALL, B. \& BASCOE, P.V. A model for C3 leaves describing the dependence of net photosynthesis on irradiance: I. Derivation. Journal of Experimental Botany, Oxford, 31(120):29-39, 1980.

QUATTAR, S.; JONES, RJ. \& CROOKSTON, R. Effect of water deficit during grain filling on the pattern of maize kernel growth and development. Crop Science, Madison, 27(4):726730, 1987.

REICHARDT, K. Processos de transferência no sistema soloplanta-atmostera. 4.ed. Campinas, Pundaça Cargill, 1985. 445p.

SWANK, J.C.; BELOW, F.E; LAMBERT, RJ. \& HAGEMAN, R.H. Interaction of carbon and nitrogen metabolism in the productivity of maize. Plant Physiology, Lancaster, 70(4):1185$-1190,1982$.

TOLLENAAR, M. Sink-source relationships during reproductive development in maize: a review. Maydica, Bergamo, 22(2):49. $-75,1977$.

TURNER, N.C. \& BEGG, J.E. Plant-water relations and adaptation to stress. Plant and Soil, The Hague, 58(1/3):97-131, 1981.

WESTGATE, M.E. \& BOYER, J.S. Carbohydrate reserves and reproductive development at low leaf water potentials in maize. Crop Science, Madison, 25(5):762-769, 1985.

YOSHIDA, S.; FORNO, D.A. \& COCK, J.H. Laboratory manual for physiological studies of rice. Los Baños, IRRI, 1971. 61p. 